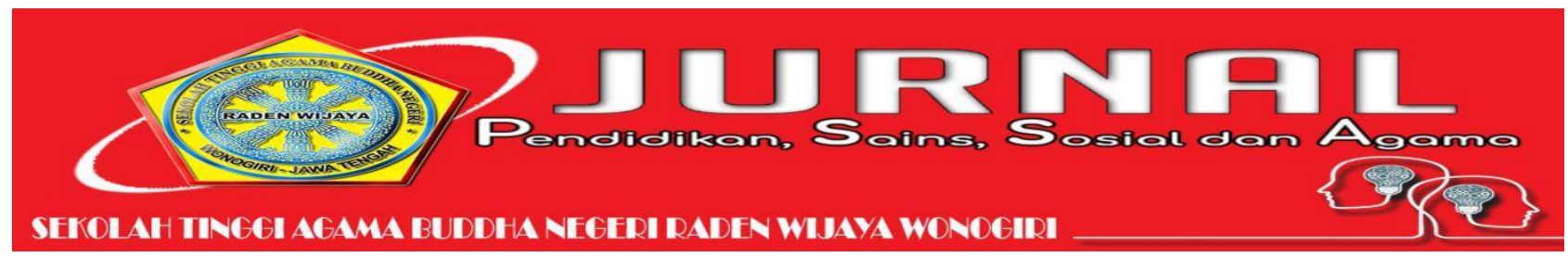

\title{
PENINGKATAN PEMAHAMAN ABHIDHAMMA PITAKA MELALUI MIND MAPPING PADA MAHASISWA SEKOLAH TINGGI AGAMA BUDDHA NEGERI RADEN WIJAYA WONOGIRI
}

\author{
Tri Suyatno \\ Sekolah Tinggi Agama Buddha Negeri Raden Wijaya Wonogiri Jawa Tengah \\ Trisuyatno@radenwijaya.ac.id
}

\begin{abstract}
Abstrak
Abhidhamma pitaka merupakan salah bagian dari kitab suci Tripitaka. pembelajaran Abhidhamma dapat dikatakan mata kuliah yang sulit karena berisikan ajaran metafisika dalam agama Buddha dimana banyak terdapat bahasa Pali dan berbagai istilah yang ada di dalamnya, banyaknya bagan. Dengan menggunakan metode mind mapping dapat memudahkan pemahamanan materi Abhidhamma Pitaka. Tujuan dari pelaksanaan rancangan aktualisasi yang akan dilaksanakan di STABN Raden Wijaya Wonogiri yaitu: (1) Untuk mengetahui penerapan pelaksanaan pembelajaran Daring Synchronous pada mata kuliah Abhidhamma Pitaka berbasis google meet (2) Untuk mengetahui penerapan pelaksanaan pembelajaran daring Synchronous pada kuliah Abhidhamma Pitaka dengan metode Mind Mapping berbasis google meet, (3) Untuk mengetahui dan meningkatkan Pemahaman siswa terhadap mata kuliah Abhidhamma Pitaka menggunakan metode Mind Mapping. Berdasarkan hasil evaluasi pretest dan posttest didapakan hasil bahwa : (1) Pretest terhadap mahasiswa mendapatkan 11 mahasiswa dengan nilai sedang dengan rentan 77-55 poin, setelah diberikan posttest pemahaman mahasiswa meningkat dari nilai terendah 20 dan setelah posttest menjadi 65, dan nilai sedang sebanyak 13 mahasiswa dengan rentan nilai 87-85, dan mengalami cukup siginifikan pada nilai tertinggi 100 point menjadi 6 mahasiswa.

(2) Berdasarkan hasil tersebut dapat disimpulkan bahwa media mind mapping dapat meningkatkan pemahaman mahasiswa.
\end{abstract}

Kata kunci: Mindmap, Buddha, Abhidhamma.

\begin{abstract}
The Abhidhamma Pitaka is a part of the Tripitaka scriptures. Abhidhamma learning can be said to be a difficult subject because it contains the teachings of metaphysics in Buddhism where there is a lot of Pali language and various terms in it, many charts. Using the mind map method can make it easier to understand the Abhidhamma Pitaka material. The objectives of the implementation of the actualization plan that will be carried out at the STABN Raden Wijaya Wonogiri are: (1) To determine the implementation of Synchronous Online learning implementation in the Abhidhamma Pitaka course based on google meet (2) To determine the implementation of Synchronous online learning implementation in Abhidhamma Pitaka lectures with the Mind method Mapping based on google meet, (3) To find out and improve students' understanding of the Abhidhamma Pitaka course using the Mind Mapping method. Based on the results of the pretest and posttest evaluations, the results showed that: (1) The pretest of students got 11 students with moderate scores with a vulnerability of 77-55 points, after being given the posttest the students' understanding increased from the lowest score of 20 and after the posttest it became 65, and the average score was 13 students with a vulnerable score of 87-85, and experienced quite a significant score at the highest score of 100 points to 6 students. (2) Based on these results, it can be concluded that mind mapping media can improve students' understanding.
\end{abstract}

Keywords: Mindmap, Buddha, Abhidhamma. 


\section{PENDAHULUAN}

Dalam undang-undang Republik indonesia nomor 5 tahun 2014 dijelaskan bahwa ASN dan Pegawai pemerintah dengan perjanjian kerja (PPPK). Dalam peraturan tersebut dijelaskan bahwa Pegawai Negeri Sipil yang selanjutnya disingkat PNS adalah warga negara Indonesia yang memenuhi syarat tertentu, diangkat sebagai Pegawai ASN secara tetap oleh pejabat pembina kepegawaian untuk menduduki jabatan pemerintahan, sementara itu Pegawai Pemerintah dengan Perjanjian Kerja yang selanjutnya disingkat PPPK adalah seorang warga negara Indonesia (guru) yang dapat memenuhi syarat tertentu, yang diangkat berdasarkan perjanjian kerja.

Manajemen ASN adalah merupakan suatu pengelolaan pegawai negeri sipil yang menghasilkan PNS yang profesional, memiliki etika, bebas dari KKN. Selain itu sistem informasi dan data ASN yang disusun secara terintegrasi dan berbasis teknologi. Dalam peraturan LAN No. 5 tahun 2014 menjelaskan bahwa seorang CPNS atau ASN harus melaksanakan ujicoba atau masa percobaan selama satu tahun sebelum dilantik menjadi seorang PNS atau ASN.

Peraturan LAN Nomor 5 tahun 2014 pada poin a dijelaskan bahwa Calon ASN harus melaksanakan pelatihan dasar calon Pegawai Negeri Sipil yang disesuaikan dengan dinamika pengembangan kompetensi. Dalam Perlan nomor 1 tahun 2021 dikemukakan bahwa Pelatihan dasar CPNS memadukan syncronus dan asyncronus Pedoman penyelenggaraan pelatihan dasar CPNS LAN No. 93/K.1/PDP.07/2021 dijelaskan bahwa Calon Pegawai Negeri Sipil wajib menjalani masa percobaan yang dilaksanakan melalui proses pelatihan terintegrasi untuk membangun integritas moral, kejujuran, semangat dan motivasi nasionalisme serta Peserta mampu menginternalisasi, menerapkan, dan mengaktualisasikan, serta membuatnya menjadi kebiasaan (habituasi), serta merasakan manfaatnya, sehingga terpatri dalam dirinya sebagai karakter Pegawai Negeri Sipil yang profesional sesuai bidang tugas sesuai dengan nilai-nilai dasar PNS.

Rancangan Aktualisasi adalah kebutuhan seseorang untuk mampu mengekspresikan diri dan mampu menjadikan dirinya sesuai dengan potensi dan dengan potensi yang dimiliki (Maslow.1954:46). Rancangan aktualisasi bagi peserta latsar adalah sebuah keharusan yang harus dipenuhi dan memberikan dampak yang baik terhadap instansi. Sementara itu rancangan ini harus bersifat aktual dan harus segera diselesaikan dan untuk meningkatkan mutu terhadap pelayanan publik Pelatihan dasar CPNS menekankan pada aktualisasi ANEKA Akuntabilitas, Nasionalisme, Etika Publik, Komitmen mutu dan anti korupsi.

STABN Raden Wijaya adalah perguruan tinggi keagaman buddha memiliki komitmen yang terbuat dalam visi " maju dalam ilmu pengetahuan, spiritual dan budaya pada tahun 2025" dan sebagai upaya untuk mewujudkan visi tersebut STABN Raden Wijaya memiliki misi yaitu yaitu a) Menyelenggarakan pendidikan dalam bidang kependidikan serta bidang non kependidikan untuk menghasilkan manusia unggul yang mengutamakan ketaqwaan, kemandirian, dan kecendikian; b) Menyelenggarakan kegiatan penelitian, dan menyebarluaskan ilmu pengetahuan, seni dan/atau budaya, yang berguna bagi masyarakat; c) Menyelenggarakan kegiatan pengabdian dan pemberdayaan masyarakat yang mendorong pengembangan potensi masyarakat; dan d) Menyelenggarakan tata kelola yang baik, bersih, dan akuntabel.

Dalam UU nomor 14 tahun 2015 tentang guru dan dosen,pada poin a dijelaskan bahwa seorang Dosen adalah tenaga pendidik yang profesional dan mengemangkan penelitian, mentransformasikan, mengembangkan, dan menyebarluaskan ilmu pengetahuan, perkembangan teknologi dan seni melalui pendidikan, penelitian, dan pengabdian kepada masyarakat. Sementara itu dalam undang-undang tersebut dijelaskan tentang bagaimana kewajiban seorang dosen.

Sebagai seorang seorang dosen wajib menjalankan dan melaksanakan tugas pokok seorang dosen adalah Dosen adalah pendidik profesional dan ilmuwan dengan tugas utama mentransformasikan, mengembangkan, dan menyebarluaskan ilmu pengetahuan, teknologi, dan seni melalui pendidikan, penelitian, dan pengabdian kepada masyarakat (Nomor 37 Tahun 2009).

Mata kuliah Abhidhamma Pitaka merupakan mata kuliah wajib bagi prodi keagamaan Buddha, hal ini dikarenakan Abhidhamma 
pitaka merupakan salah bagian dari kitab suci Tripitaka. Banyak kendala yang dialami mahasiswa ketika belajar Abhidhamma dan kendala utamanya disebabkan karena pandemi covid 19, dan penyampaian materi dirasa kurang maksimal dan optimal. Selanjutnya pembelajaran Abhidhamma dapat dikatakan mata kuliah yang sulit karena berisikan ajaran metafisika dalam agama Buddha dimana banyak terdapat bahasa Pali dan berbagai istilah yang ada di dalamnya, banyaknya bagan dan akan menghasilkan kurangnya minat mahasiswa, hal tersebut dapat menjadi kendala yang dialami oleh mahasiswa, dan membutuhkan metode yang dapat meningkatkan pemahaman mahasiswa. Berdasarkan latar belakang dan pengamatan yang telah dipaparkan di atas, sebagai pelaksanaan dari Tri Dharma Perguruan tinggi dalam hal ini maka penulis menyusun rancangan dan memfokuskan kepada bagaimana mencari solusi dari kurangnya pemahaman mahasiswa dalam mengikuti dan mempelajari perkuliahan Abhidhamma dengan judul "Peningkatan Pemahaman Abhidhamma Pitaka Melalui Mind Mapping Pada Mahasiswa Sekolah Tinggi Agama Buddha Negeri Raden Wijaya Wonogiri”.

\section{METODE}

Pendekatan yang diguakan adalah kuantitatif dengan dengan desain pengembangan media mind mapping pada mata kuliah Abhidhamma Pitaka.

Motode pegumpulan data menggunakan metode Pre test dan Posttest dan dianalisis menggunakan Ms. Excel untuk mendapatkan peningkatan hasil penggunaan media mind mapping.

\section{HASIL}

Berdasarkan pelaksanaan aktualisasi didapatkan data pre test dan post test yang diberikan kepada mahasiswa selain itu juga melaksanakan evaluasi terhadap pembelajaran (metode yang digunakan).

a. Analisis Pre Test dan Post Test

\begin{tabular}{|c|l|l|l|}
\hline \multirow{2}{*}{ No } & \multirow{2}{*}{ Nama } & \multicolumn{2}{|c|}{ Skor } \\
\cline { 3 - 4 } & & Pretest & Post Test \\
\hline 1 & Ajivo Hendarcho & 50 & 75 \\
\hline 2 & Aprilisa Pratiwi & 25 & 85 \\
\hline
\end{tabular}

\begin{tabular}{|c|l|l|l|}
3 & Ari Dwi Atmono & 50 & 65 \\
\hline 4 & Ari Suryana & 85 & 95 \\
\hline 5 & Budi Tri Apriyanto & 70 & 70 \\
\hline 6 & Dani pratama & 35 & 80 \\
\hline 7 & Della Prawitasari & 70 & 75 \\
\hline 8 & Dian Ayu Eka P & 20 & 85 \\
\hline 9 & Dwi Aningsih & 85 & 100 \\
\hline 10 & Eka Ratana Candra & 50 & 85 \\
\hline 11 & Irfani Dhanu Marta & 60 & 100 \\
\hline 12 & Kanti & 45 & 65 \\
\hline 13 & Mardian Prasetyo & 80 & 100 \\
\hline 14 & Meta Wiras Astuti & 40 & 100 \\
\hline 15 & Metta Budiyanti & 75 & 100 \\
\hline 16 & Mita Dammayanti & 80 & 80 \\
\hline 17 & Randi Pratama & 45 & 75 \\
\hline 18 & Ricky Guntur B.L & 20 & 70 \\
\hline 19 & Sri Hartini & 60 & 100 \\
\hline 20 & Sunaryono & 50 & 75 \\
\hline 21 & Wulandari & 65 & 80 \\
\hline
\end{tabular}

Analisi dari hasil pre test

1. Nilai tertinggi dari Pretest adalah 85 dan terendah adalah 20 dengan nilai rata-rata adalah 55. Hal ini dapat disebabkan karena mahasiswa belum mendalami pembelajaran dan belum dilaksanakannya Aktualisasi.

2. Nilai Tertinggi dalam Post test ini adalah 100 sebanyak 6 mahasiswa, dan nilai terendah adalah 65 sebanyak 2 mahasiswa dengan rata-rata nilai 84 . Hal ini pengaruhi dengan adanya pelaksanaan aktualisasi kepada mahasiswa Pendidikan keagaman Buddha dengan metode mind mapping.

Untuk mengetahi rentan dari hasil pretest maka dapat dikategorikan menjadi tiga yaitu rendah, rendah dan tinggi. Adapun rumus yang digunakan untuk mengetahui pengkategorian dalam pre test sebagai berikut :

$\mathrm{Nt}$ : Nilai Tertinggi

$$
\frac{N t-N r+1}{k}
$$

$\mathrm{Nr}$ : Nilai Tendah

$\mathrm{K}$ : Jumlah Kategori 


\section{Pretest}

Berdasarkan dari hasil pelaksanaan pretest (tabel 3.2) pada mahasiswa semester 5 di Pendidikan Keagaman Buddha di STAB Negeri Raden Wijaya Wonogiri Jawa Tengah.

$$
\frac{N t-N r+1}{k}=\frac{85-20+1}{3}=22
$$

Rentan nilai yang didapatkan dari hasil analisis adalah 22 point, maka berdasarkan hasil tersebut di buat tabel untuk menganalisa dan memahami pengukuran skor sebagai berikut :

Tabel Kategori

\begin{tabular}{|l|l|l|}
\hline No & Rentan & Kategori \\
\hline 1 & $100-78$ & Tinggi \\
\hline 2 & $77-55$ & Sedang \\
\hline 3 & $<54$ & Rendah \\
\hline
\end{tabular}

Berdasarkan hasil tersebut dapat diklasifikasikan rentan kategori yang digambarkan dalam diagram berikut ini :

\section{Kategori Pretest}

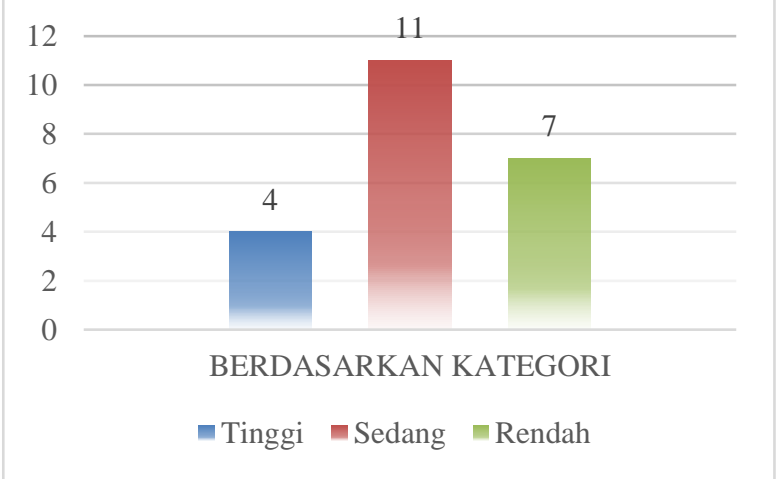

Pretest terhadap mahasiswa mendapatkan 11 mahasiswa dengan nilai sedang dengan rentan $77-55$ poin atau sekitar $50 \%$.

2. Post test

\begin{tabular}{|c|l|l|l|}
\hline \multirow{2}{*}{ No } & \multicolumn{2}{|c|}{ Nama } & \multicolumn{2}{|c|}{ Skor } \\
\cline { 3 - 4 } & & Pretest & $\begin{array}{c}\text { Post } \\
\text { Test }\end{array}$ \\
\hline 1 & Ajivo Hendarcho & 50 & 75 \\
\hline 2 & Aprilisa Pratiwi & 25 & 85 \\
\hline 3 & Ari Dwi Atmono & 50 & 65 \\
\hline 4 & Ari Suryana & 85 & 95 \\
\hline 5 & Budi Tri Apriyanto & 70 & 70 \\
\hline 6 & Dani pratama & 35 & 80 \\
\hline
\end{tabular}

Asosiasi Dosen \& Unit Penelitian dan Pengabdian Masyarakat

\begin{tabular}{|c|l|l|l|}
7 & Della Prawitasari & 70 & 75 \\
\hline 8 & Dian Ayu Eka P & 20 & 85 \\
\hline 9 & Dwi Aningsih & 85 & 100 \\
\hline 10 & Eka Ratana Candra & 50 & 85 \\
\hline 11 & Irfani Dhanu Marta & 60 & 100 \\
\hline 12 & Kanti & 45 & 65 \\
\hline 13 & Mardian Prasetyo & 80 & 100 \\
\hline 14 & Meta Wiras Astuti & 40 & 100 \\
\hline 15 & Metta Budiyanti & 75 & 100 \\
\hline 16 & Mita Dammayanti & 80 & 80 \\
\hline 17 & Randi Pratama & 45 & 75 \\
\hline 18 & Ricky Guntur B.L & 20 & 70 \\
\hline 19 & Sri Hartini & 60 & 100 \\
\hline 20 & Sunaryono & 50 & 75 \\
\hline 21 & Wulandari & 65 & 80 \\
\hline
\end{tabular}

Nilai Tertinggi dalam Post test ini adalah 100 sebanyak 6 mahasiswa, dan nilai terendah adalah 65 sebanyak 2 mahasiswa dengan rata-rata nilai 84 . Hal ini pengaruhi dengan adanya pelaksanaan aktualisasi kepada mahasiswa Pendidikan keagaman Buddha dengan metode mind mapping.

Berdasarkan dari hasil pelaksanaan pretest (tabel 3.2) pada mahasiswa semester 5 di Pendidikan Keagaman Buddha di STAB Negeri Raden Wijaya Wonogiri Jawa Tengah.

$$
\frac{N t-N r+1}{k}=\frac{100-65+1}{3}=12
$$

Rentan nilai yang didapatkan dari hasil analisis adalah 12 point, maka berdasarkan hasil tersebut di buat tabel untuk menganalisa dan memahami pengukuran skor sebagai berikut :

\section{Tabel Kategori}

\begin{tabular}{|l|l|l|}
\hline No & \multicolumn{1}{|c|}{ Rentan } & \multicolumn{1}{c|}{ Kategori } \\
\hline 1 & $100-88$ & Tinggi \\
\hline 2 & $87-75$ & Sedang \\
\hline 3 & $<74$ & Rendah \\
\hline
\end{tabular}

Berdasarkan hasil tersebut dapat diklasifikasikan rentan kategori yang digambarkan dalam diagram berikut ini : 


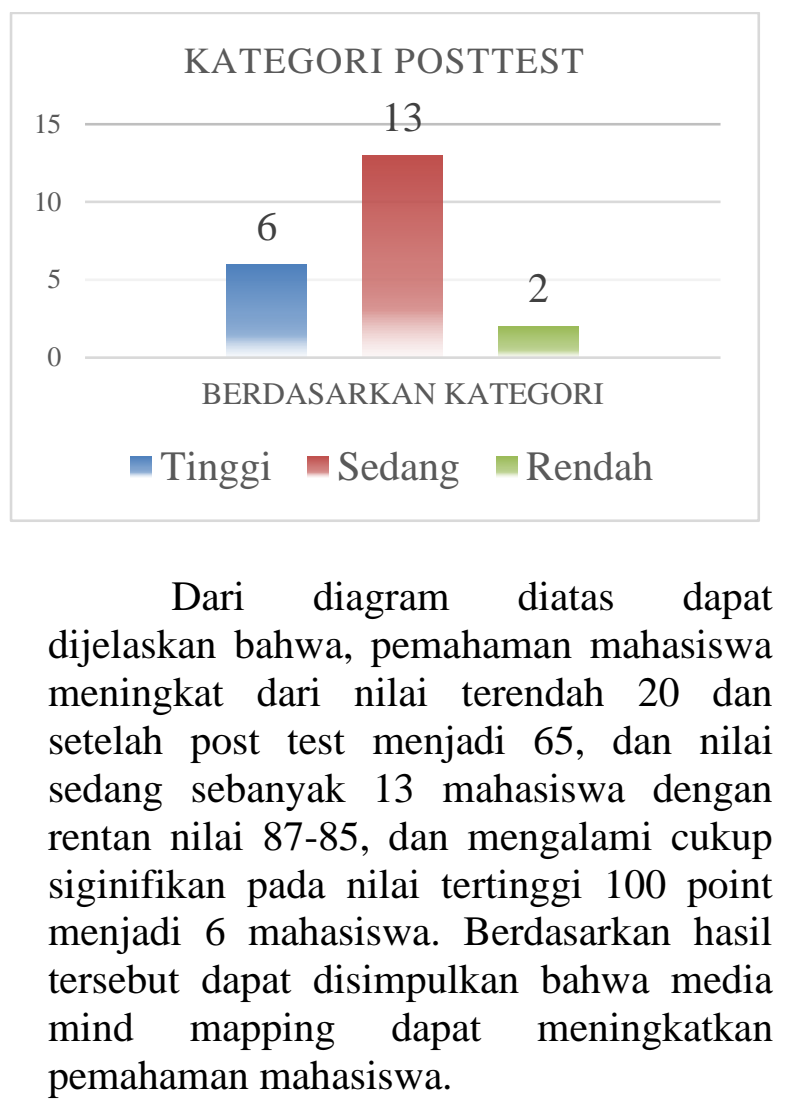

\section{KESIMPULAN}

Berdasarkan hasil evaluasi pretest dan post test didapakan hasil bahwa Pretest terhadap mahasiswa mendapatkan 11 mahasiswa dengan nilai sedang dengan rentan 77-55 poin atau sekitar $50 \%$, setelah diberikan post test pemahaman mahasiswa meningkat dari nilai terendah 20 dan setelah post test menjadi 65 , dan nilai sedang sebanyak 13 mahasiswa dengan rentan nilai 8785 , dan mengalami cukup siginifikan pada nilai tertinggi 100 point menjadi 6 mahasiswa. Berdasarkan hasil tersebut dapat disimpulkan bahwa media mind mapping dapat meningkatkan pemahaman mahasiswa.

\section{DAFTAR PUSTAKA}

Perlan Nomor 14 Tahun 2005 Tentang Guru dan Dosen

Undang-Undang Republik Indonesia Nomor 37 Tahun 2009 tentang Aparatur Sipil Negara

Undang-Undang Republik Indonesia Nomor 5 Tahun 2014 tentang Aparatur Sipil Negara
Pedoman penyelenggaraan pelatihan dasar CPNS LAN No. 93/K.1/PDP.07/2021

Peraturan LAN Nomor 1 Tahun 2021 Tentang Pelatihan Dasar Calon Pegawai Negeri Sipil (Latsar CPNS)

https://radenwijaya.ac.id/?page_id=832 